\title{
From Segregation to Integration of New Developments in Historic Contexts: Rural Texture in Iran
}

\author{
Azadeh LAK', Reihaneh AGHAMOLAEI'², Eftekhar AZIZKHANI ${ }^{1}$ \\ ${ }^{1}$ Shahid Beheshti University, Faculty of Architecture and Urban Planning, Department of Regional, Urban Planning and Design, Tehran, IRAN \\ ${ }^{2}$ University of Tehran, College of Fine Arts, Tehran, IRAN \\ E-mail: a_lak@sbu.ac.ir, r.ghamolaei@ut.ac.ir, eftekhar_azizkhani@yahoo.com \\ DOI: 10.24193/JSSP.2018.1.06 \\ https://doi.org/10.24193/JSSP.2018.1.06
}

K e y w o r d s: rural texture, integration, development, segregation, Iran

\begin{abstract}
A B S T RA C T
During the last century, rapid growth in human settlements has caused the fragmentation of spatial structure of urban and rural areas. This study explores the dimensions of physical integration between new and old developments of human settlements. In this regard, a mixed-method was applied for Qehi village as a historic place in two steps. In phase 1, about 20 residents were asked to discuss their perception about physical integration between the old and new parts of their settlement. Then, a 16-item questionnaire was developed based on the interview responses, literature review and field observation. In phase 2, the self-reported questionnaire was incorporated into the results of interview with 34 architects, urban planners and designers that worked in the Qehi development project. The experts' insights were analyzed and fitted into 4 effective categories of physical integration. Finally, the validity of mentioned dimensions was conducted by confirmatory factor analysis (CFA) in SPSS and AMOS. This paper illustrates the confirmed dimensions, namely connectivity, anchor points' continuity, continuity of the place identity, and quality of life for the physical integration. The findings of this research can be applied as a model for new developments especially in the case of rural settlements.
\end{abstract}

\section{INTRODUCTION}

During the last century, rapid modern growth in human settlements has resulted in slicing into traditional settings and dichotomy of old traditional parts of the town on one hand and newly zoned areas on the other in the case of emergent countries. These new zones differ spatially, physically and socioeconomically, as well as culturally resulting in a mosaic urban area without any proper center [1]. Thus, physical form is considered as one of the most significant parameters in rapidly growing cities and villages. In the last decades, modern urban planning and projects have led to segregation and fragmentation in Iran, which is in contrast to the features of traditional cities [2]. Moreover, the spatial structure of Iranian settlements, affected by technology and modern life style, coincided with the decline of rural values and their original sociocultural identities [3].

The present study attempts to investigate a theoretical model to integrate the new and the old parts of Qehi village. This historic village has been divided into two parts by the new development processes: organic and grid textures. The new development of Qehi was based on the modern grid pattern, which is completely in contrast to the traditional patterns of Iranian settlements. This research investigates how physical and social structures of a particular settlement can be integrated based on the views of both residents and specialists. Therefore, a mixed method (qualitative and quantitative) was applied to explore the main dimensions of integration. In the following sections, after reviewing the literature and highlighting the most important factors, the framework was defined. Then, 
the model was assessed through sequential qualitativequantitative process, and necessary modifications were applied. In the discussion section, the four dimensions of connectivity, anchor points continuity, continuity of the place identity, and quality of life are recognized as effective parameters for the integration of Qehi development.

\subsection{Physical segregation and integration}

Researchers have mentioned the significance of reductions in physical segregation [4]. Segregation, as a spatial concept, means the separation or isolation from the built form [4], [5]. Segregation is usually defined as a result of social causes in physical divisions or in the formation process of ghettos [6]. Julienne Hanson (2000) argued that the spatial structure of built environments affects the degree of socio-economic interaction between people, being able to isolate their residents from other environments and limiting the activities carried out in the everyday life [7]. According to literature, there are different parameters intensifying segregation based on each context. For instance, some sources consider poor accessibility as an important factor preventing people to participate as members of a society [4]. According to others, high accessibility attracts activities specially those requiring movement with multiplier effect because they will increase the significance of the locations themselves and in turn encourage further uses [8]. This dynamic process was called a "movement economy" which includes configuration, attraction and movement [8]. Segregation can be categorized as four groups with focus on typology of boundaries: enumerative, municipal, physical, and symbolic; these are not mutually exclusive [9]. Therefore, different studies have developed indices and effective parameters to define segregation boundary.

Since the late 1960s, different integration programs were presented to solve the segregation issue. Two generations with the first one focusing on reversing past discrimination with open housing movement basis leading to the unitary housing market and promoting integration could be idntified [10]. The second one includes poverty concentration as a 'new problem' with focus on mobility and the redevelopment of socially mixed housing.

Ellin (2006) has explored 5 qualities of integral urbanism as hybridity, connectivity, porosity, authenticity and vulnerability [11]. Hybridity and connectivity are effective parameters to consider people and nature as members of a whole system, working together, as well as building and landscape. Besides, porosity activates mutual access for both nature and people through permeable membranes rather than postmodern fortification and modernist dismantle boundaries [11].
The urban fabrics neglecting the traditional values have been criticized. According to this theory, buildings are parts of the larger fabric such as streets, squares, and viable open space. Growth patterns should consider the three dimensional relationships between buildings, spaces and a real understanding of human behavior [12]. The same source proposed a method that is based on the combination of three theories (figureground, linkage, and place) that could be used to integrate lost spaces [12]. This concept is based on defining the space, creating a connection network and finally considering human needs with their social, historical and cultural contexts [12], [13].

\section{CASE STUDY}

Qehi village, with a history of more than 850 years is located in the eastern part of Isfahan, one of the famous and historic provinces of Iran, in the desert part of the country. The architectural style of Old Qehi consists of a unique combination of houses, mosques, bazaars, traditional mills, passes and āb anbār, which is a traditional reservoir or cistern of drinking water in Greater Iran in antiquity [14]. Two distinct parts are visible in the fabric of Qehi village. First, the historical core is characterized by organic and vernacular architecture and building materials. The new neighborhoods, located in the north and south of the village were built in the last twenty years. They do not follow the historical architectural style and have caused significant damage to the natural landscape. Unfortunately, in time, many people moved to the newer neighborhoods abandoning the old core (Fig. 1).

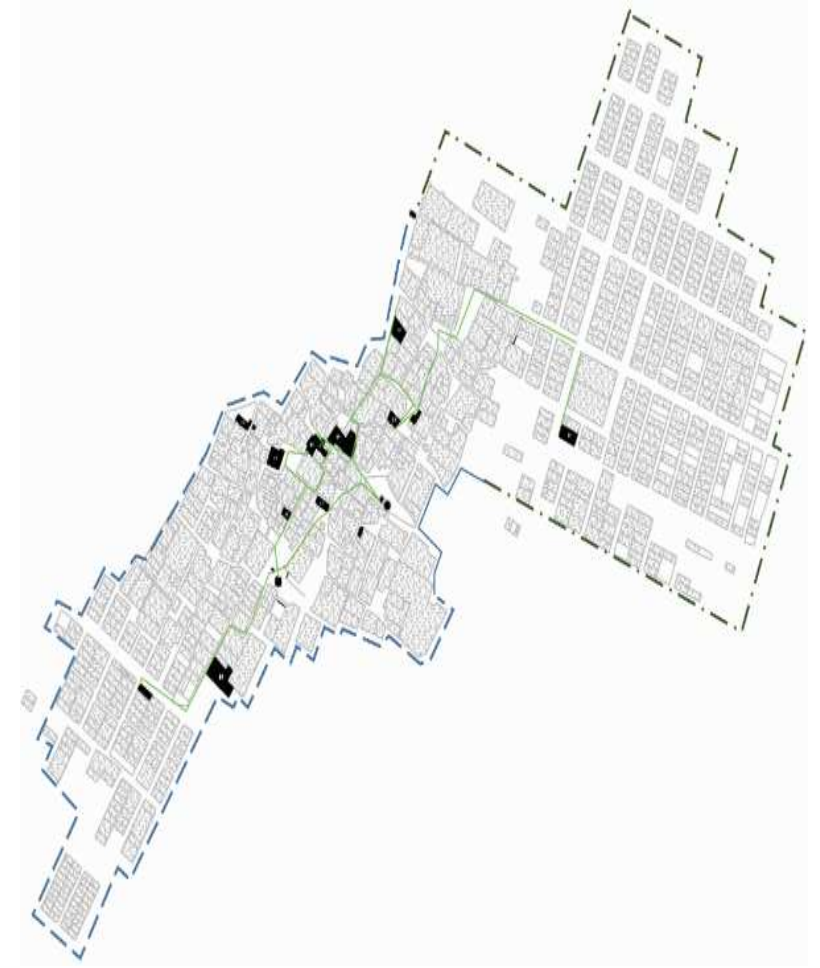

Fig. 1. The distinct segregation between new neighborhoods and the old part of the village. 


\section{METHODOLOGY}

This study has applied the sequential mixed method in two related phases, one using qualitative (phase 1) and the other quantitative method (phase 2).

Phase 1 included desk study, field study and content analysis. Three fundamental theories developed by Trancik including figure-ground, linkage and place are considered as the observation techniques to study Qehi's segregation [12]. Firstly, we reviewed the literature to formulate theoretical framework and identify characteristics of the case. Secondly, using the Trancik theory as the theoretical base, trained observers examined the characteristics of Qehi village [12]. Since the public perceptions are different from experts judgments, more emphasize should be considered on both experts and lay perspectives [15], [16]. In this regard, in-depth interviews with local residents were conducted until achieving data saturation. The interviewees were chosen based on the snowball method from local residents in Qehi. In this regard, 10 face-to-face interviews were conducted from September to December 2014, each lasting on average 20 minutes. They were questioned on their perceptions of linkages between the two parts of the village. All interviews were recorded by people permission and transcribed to extract concepts and thematic categories.

The final step of phase 1 put together a theoretical framework through the "content analysis". Then, the model how to integrate new and old parts of Qehi was developed. The model focuses on four main themes based on local residents' perception. The validity of model was examined using confirmatory factor analysis in Phase 2.

In the second phase, data was collected through questionnaires to explore the specialists' experiences about integration between old and new fabrics. These experts have worked as architects, urban planners and designers in Qehi since 1985. The insights of these 35 people were analyzed and fitted into four different groups. Then, the confirmatory factor analysis (CFA) method was applied for validating the proposed model. In next sections, findings and results for each phase are presented sequentially. Figure 2 synthetically depicts the methodology of this research and components of each phase.

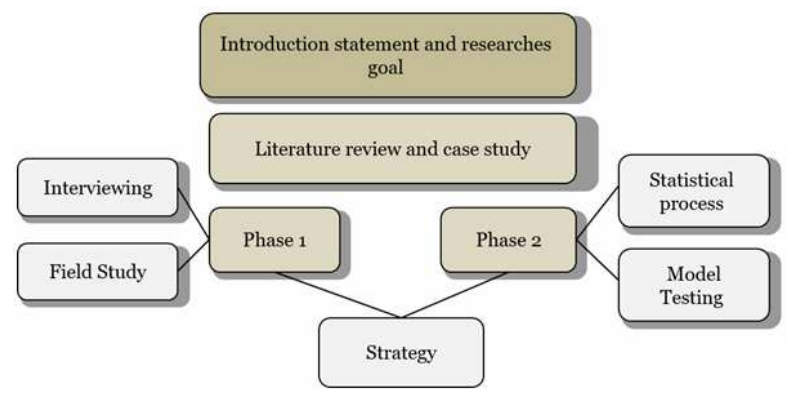

Fig. 2. The research methodology.

\section{RESULTS}

\subsection{Results of phase 1}

Interview analysis has revealed that most interviewees experienced the integration between two parts by physical features. Actually, these features were grouped into four general categories that composed the content of the subsequent survey instrument in Phase 2. After reviewing all data in the qualitative phase and synthesizing participants' responses, these dimensions were extracted as connectivity, continuity of anchor points (places), continuity of the place identity and quality of life and they are depicted in Figure 3.

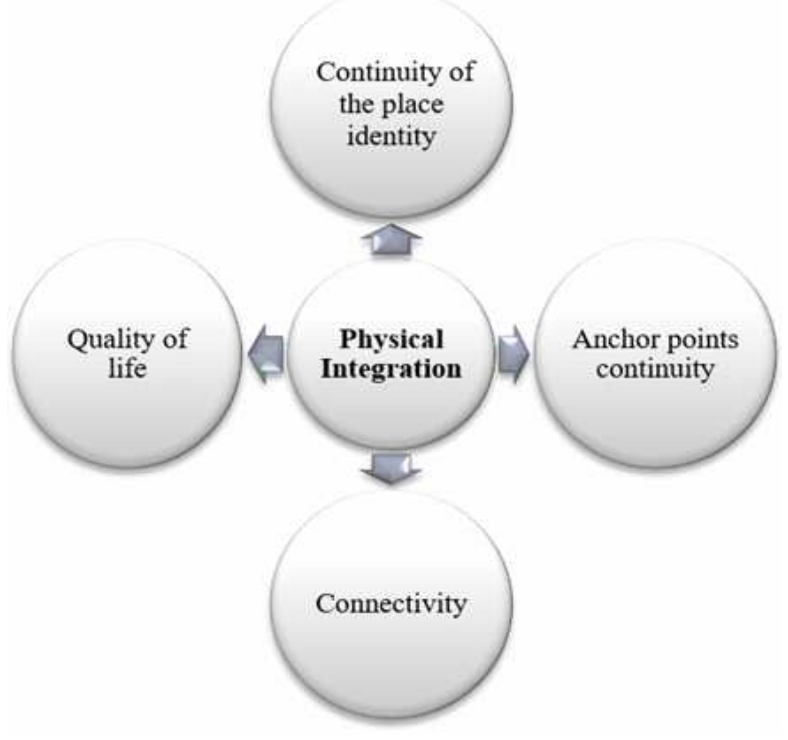

Fig. 3. Proposed Model as a result of Phase 1.

Connectivity. Connectivity as continuity of access is a vital dimension to integrate people, functions and places in the two parts of the village. The differences between network patterns (grid and organic) and dominance of cars have significant effects on the level of connectivity perceptions.

Continuity of anchor points (places). Based on Tranciks' place theory, the presence of historical places is essential to reclaim local identity in new neighborhoods. However, natural context, historical landscape, traditional architecture style and finally local residents' beliefs are ignored. Meanwhile, religious places for holding events play a significant role in old Qehi's residents, but such event places cannot be found in new part of the village. The results reveal that distinctiveness of boundaries highlights the two patterns of the village (organic and grid). The lack of required amenities in the old part of the village after developing process has made it disabled to satisfy the people's modern lifestyle. Our findings show that lost spaces and different architectural styles lead to highlight a distinct boundary between the two parts. This boundary is known as the most important obstacle 
for physical cohesion. Previous studies have also emphasized the need for homogenous public spaces to create a major structure for reconnecting the two parts [11]. Additionally, integrating a variety of functions, activities and social groups leads to high quality and durability of space.

The continuity of the place identity. Although most parts of the old village are already destroyed, almost all interviewees consider the old fabric as part of their identity. People usually complained about the destruction of this valuable part of the village lamenting about the loss of originality and identity. The most interviewees mentioned that they have emotional bond to the old part especially because of their memories and ancient origins.

The quality of life. About $80 \%$ of residents prefer to live in new neighborhoods due to the higher level of life quality there. One of the most important elements of life quality is accessibility to basic and fundamental facilities including urban infrastructures, which are not provided in the old part. According to local residents, the quality of life in newer parts is higher than in the old part of the village, especially based on some qualities, such as security, safety and convenience. Therefore, they have accepted the new part as a better place for life compared to historic fabric in Qehi.

\subsection{Results of phase 2}

In the second phase of the study, the questionnaire was used to collect data from 35 urban planner specialists, designers and architects, which were asked to explore factors for connecting the two parts of the village. Based on categories determined during the interviews conducted in Phase 1, the questionnaire was designed with a brief 16-item scale to measure different types of physical integration. The respondents were asked to choose between four possible answers: very little $=1$, little $=2$, much $=3$, very much $=4$. The confirmatory factor analysis was used to validate the hybrid model by phase 1 , which was based on the field study and on the description of people's perceptions (Table 1).

Table 1. Reference questionnaire.

\begin{tabular}{|c|c|c|c|c|c|c|}
\hline $\mathbf{V}$ & Theme & Question & $\begin{array}{l}\text { Very } \\
\text { low }\end{array}$ & Low & High & $\begin{array}{l}\text { Very } \\
\text { high }\end{array}$ \\
\hline V1 & \multirow{4}{*}{ 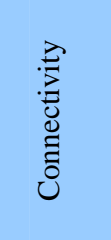 } & Connectivity of roads network in new and old part of Qehi & & & & \\
\hline V2 & & Connectivity of roads and public space through landscape promotion & & & & \\
\hline V3 & & Continuity of commercial-religious and service uses & & & & \\
\hline V4 & & Construction in abounded urban blocks with traditional material & & & & \\
\hline V5 & \multirow{5}{*}{ 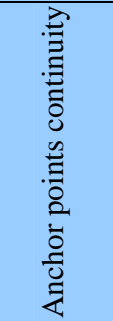 } & Renovation of monuments & & & & \\
\hline V6 & & Connectivity of commercial-religious and service uses through paced ways & & & & \\
\hline V7 & & Construction of religious monuments in newer part of Qehi & & & & \\
\hline V8 & & The continuity of buildings in new and old part of Qehi & & & & \\
\hline V9 & & The continuity of main road in new and old part of Qehi & & & & \\
\hline V10 & \multirow{4}{*}{ 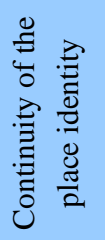 } & Religious ceremonies and rituals & & & & \\
\hline V11 & & More social interaction residents of two parts of Qehi & & & & \\
\hline V12 & & Renovation of old fabric to attract tourist especially for tradition part & & & & \\
\hline V13 & & Attracting tourists through rituals and special religious events & & & & \\
\hline V14 & \multirow{3}{*}{ 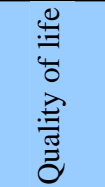 } & Diversity in new and old part of Qehi & & & & \\
\hline V15 & & Proving services for people in old part of village & & & & \\
\hline V16 & & Promotion of housing quality in old and new part of Qehi. & & & & \\
\hline
\end{tabular}

In the statistical process, different methods and tools were used to test the validity and reliability of the results. In the first stage, the reliability of questionnaire was checked through Cronbach's alpha, as a measure of internal consistency and relativity in a set of items. The alpha value above 0.7 is considered acceptable and consequently, a higher value would show reliability of elements [17]. According to table 2, 
the value of Cronbach's Alpha is about 0.914 showing high level of reliability for interactions of questionnaire.

Table 1. Cronbach's Alpha: reliability statistics.

\begin{tabular}{c|c} 
Cronbach's Alpha & No. of items \\
\hline 0.914 & 16
\end{tabular}

The next step was to conduct CFA to test the relationship among 16 questions and the relative fit of the 4-parameter model. To validate the model, CFA is run through AMOS and SPSS software [18]. In this method, measure of fit and degree of freedom were initially assessed using chi square and ( $\mathrm{d} f$ ) respectively. This method is recognized as multiple index approach in statistical literature to evaluate the validity of models.
The acceptable range of other essential values are: Root Mean Square Error, which should be less than 0.08 (RMSEA<0.08) and the comparative fit index should be more than 0.90 (CFI>0.90) [19], [20], [21], [22]. The relationships among the 16 items and the relative fit of defined construct was tested. According to table 3, the CFA results of 4-parameter construct is acceptable and shows adequate fit, more depending on the size of sample than the goodness of fit. These results showed that $x^{2}$ was equal to $101.4, \mathrm{~d} f$ was $98, x^{2} / \mathrm{df}$ was found to be 1.03, RMSEA was calculated as equal to 0.069), and CFI was 0.925. Modification indexes suggested that fit could be improved by adding covariance paths between the errors associated with items in each of the behavior domains [20]. Nevertheless, we chose not to add any speculative parameters based on modification indexes because such alterations do not accurately represent the true data structure [22], [23].

Table 2. Confirmatory factor analysis with comparison between different models.

\begin{tabular}{|c|c|c|c|c|}
\hline Model & $\mathbf{X}^{2}$ & $\mathrm{X}^{2} / \mathrm{df}$ & RMSEA & CFI \\
\hline 4-parameter & 101.458 & 1.03 & 0.069 & 0.925 \\
\hline
\end{tabular}

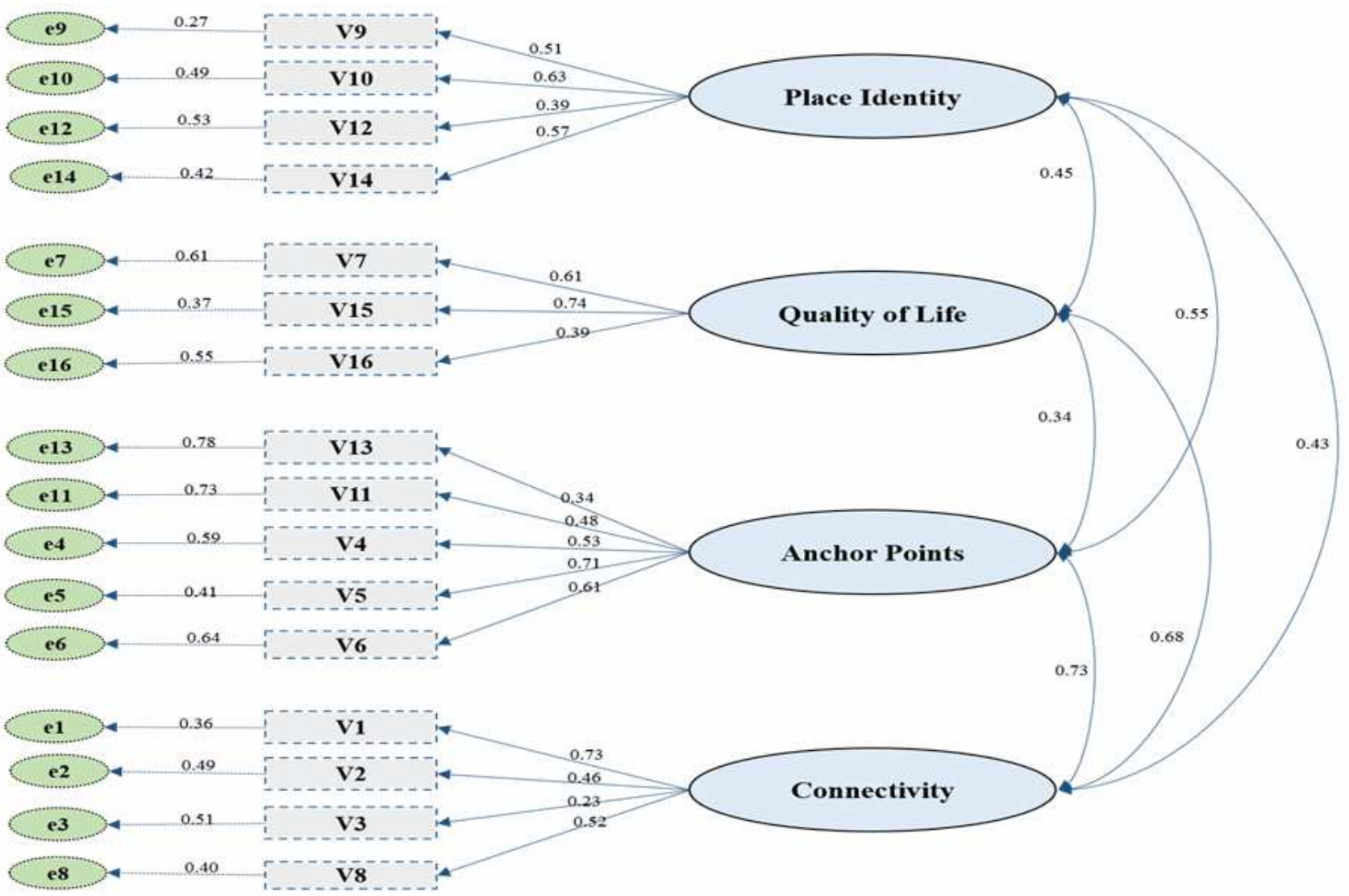

Fig. 4. Confirmatory factor analysis results for the selected 4-factor model.

A summary of the standardized values of the significant paths and covariance among observed variables in the approved four-factor measurement model is revealed in Figure 4. For choosing the well- 
fitting model, the convergent validity of the specific construct was examined by comparing standardized path loading coefficients (X). Each of the path loading was more than $0.23(\mathrm{X}>0.23)$ and all values were statistically significant, supporting the fact that each item was a relatively good measure of the specified factor. Covariance between the constructs (Q) showed that relationships between all the behavior domains were positive and statistically significant. Error variances for the observed variables ranged from 0.27 to 0.78 , indicating substantial variability in the proportion of the variance for each behavior. The CFA and associated goodness-of-fit indices supported the hypothesis that the four-factor model fits best for the observed covariance structure.

\section{DISCUSSION AND CONCLUSION}

The results and findings can be reclaimed as the well-designed model for the new development process in the history of human settlements so as to integrate the old and the new fabrics. This research introduces four dimensions including connectivity, anchor points and places continuity, continuity of the place identity and quality of life as essential materials for physical integration between these two different fabrics in residents' images. These dimensions were resulted from interviews and confirmed through statistical models.

According to the qualitative and quantitative studies, connectivity is one of the most important perceived features of physical cohesion. The continuity of roads in new and historic fabrics with more permeability and access would lead to more physical integration, especially when the characteristics of pavements and landscapes are similar in the two fabrics. In other words, the existence of similar elements would help to understand easier the connectivity. The continuance of public spaces with similar characteristics promote the perception of integration between the two fabrics. Another point is the existence of amenities and retail on the boundaries since such services will intensify the people's presence to connect different parts. Some previous studies have emphasized the importance of the connectivity for integration. Trancik (1986) introduced the corridor as an integrative parameter in linkage theory, connecting different elements of fabrics. Furthermore, developments in boundaries lead to create defined spaces which can be explained through Figure-ground Trancik's theory [12].

Ellin (2006) claims that connectivity and porosity are important factors toward concentration of activities and people [11], [13]. Although, all the previous development processes focused on the separation and differences between activities, now they are shifting towards integration and continuity of similar activities among people. To put it together, it could be considered that connectivity concept matches theories of Figure-Ground and linkage by Trancik and the integral urbanism theory by Ellin [11], [12].

The second theme investigates the role of anchor points and places continuity in integration of these two parts. Participants in this study have mentioned that continuity of places in both distinct organic and grid sections will affect their perception of cohesion. In this way, observing the set of culturalreligious places in old fabric and its continuity in new developments will mitigate the disjunction borders. In other words, the presence of religious spaces improves the common sense as its symbolic role for both groups of residents. On other hand, the coherent physical bodies and old spatial structures, which go through new developments, will intensify the sense of integration. It is worth mentioning that reorganizing the old spatial structures in the new developments improves place identity leading to promote social interactions. Attending rituals helps to perceive the integration between different parts of settlement and more familiarity for residents of the two parts as a holistic village

The Place theory developed by Trancik emphasized the cultural values of places. He argued that associated meanings are able to recreate spaces and increase the "place belongingness" and "place attachment" [12]. Ellin (2006) identified place continuity as "hybridity" intensifying the opportunities for more collaboration and interactions in both fabrics and their thresholds [11].

Place identity is the other effective dimension in promotion of cohesion. This concept demonstrated some aspects of personal identity related to physical environment [24]. In fact, "potpourri of memories, conceptions, interpretations, ideas, and related feelings about specific physical settings, as well as types of settings" help people to introduce themselves

[24]. The residents experience memories, ideas, emotions, opinions, values, and meanings are through physical environment, As Qehi can be perceived by some special characteristics including historic -organic fabric, tourist attractiveness of old monuments and buildings, religious ceremonies and rituals. These features could be beneficial in enhancing social interaction and revitalization of historic fabric due to the empowering cultural tourism. Meanwhile, these qualities promote the "sense of pride", providing tourist amenities and essential services in new development help to integrate two different parts as a whole. Promotion of these social interactions between two different parts of society help people to recognize historic Qehi as "their living place" which equals to "authenticity" concept in Ellin integral urbanism [11]. Ellin defines "authenticity" based on the physical and social conditions inspired by genuine needs of residents 
[11]. In other words, place identity is considered as one the most important dimensions to introduce the sense of self-adjusting according to Place theory by Roger Trancik emphasizing the concept of meaning [12].

The other dimension, recreating cohesion between the two parts of Qehi, is to provide sufficient quality of life for whole settlement. The necessity of life quality justifies the plans to cover problems related to cars and their parking space in both part of Qehi. The other point is to retrofit the old buildings according to people's needs and opinion. The survey participants have added the concepts of vitality and variety of building types to improve the quality of life. This diversity in terms of building types can accommodate the tastes of more residents. People who are inclined to live in traditional housing, choose the old part of village while those who are interested in modern lifestyle, choose the new part. According to the participants' opinions, improving the villagers' life style involves revitalizing and strengthening the buildings as well as improving the mechanical and electrical facilities. Also, providing equal access to tangible facilities, such as health care and education to all village inhabitants, regardless of the neighborhood they live in, would create a sense of integration. Ellin has mentioned diversity as a constituent feature of hybridity [11].

Dimensions obtained from this study focus on of physical integration between old and new developments in Qehi village, including "connectivity", "anchor points and places continuity", "the continuity of the place identity" and "the quality of life". This 4dimentional model is comparable to Ellin's model including connectivity, hybridity, prosperity, authenticity and vulnerability [11]. She recognized the importance of these fundamental features in implementing physical and integral urbanism in urban development. The three dimensions of connectivity, authenticity, and hybridity are similar to the proposed model of this research. However, this research also puts emphasis on the fourth dimension of "life quality" and access to public services, leading to perceive more integration in new developments.

\section{REFERENCES}

[1] Deffner, V., Hoerning, J. (2011), The struggle to belong, International rc21, vol. 15 .

[2] Tavallaei, N. (2002), The Integrated Urban Form, Soffeh, vol. 35, pp. 5-15.

[3] Jame, K. M. (2010), Rehabilitation of the valuable rural texture; A process from subjectiveity to objectivity.

[4] Legeby, A. (2010), Urban segregation and urban form: From residential segregation to segregation in public space.

[5] Mohamed, A. A., Vav Nes, A., Salhen, M. A., Khalifa, M. A. Johannes, H. (2014), Understanding urban segregation in CAIRO, Smart, Sustainable and Healthy Cities, p. 15.

[6] Marcuse, P. (2005), Enclaves yes, ghettos no, Desegregating the city: Ghettos, enclaves, and inequality, pp. 15-30.

[7] Hanson, J. (2000), Urban transformations: a history of design ideas, Urban design international 5(2): 97-122.

https://doi.org/10.1057/palgrave.udi.9000011

[8] Hillier, B., Hanson, J. (1984), The social logic of space CUP, Cambridge.

[9] Roberto, E. (2015), Spatial Boundaries and the Local Context of Residential Segregation, arXiv preprint arXiv:1509.02574.

[10] Goetz, E. G. (2003), Housing dispersal programs, Journal of Planning Literature18(1): 3-16. https://doi.org/10.1177/o885412203251339

[11] Ellin, N. (2006), Integral urbanism, Taylor \& Francis.

[12] Trancik, R. (1986), Finding lost space: theories of urban design, John Wiley \& Sons.

[13] Banerjee, T., Loukaitou-Sideris, A. (2011), Companion to urban design, Routledge.

[14] *** ICHTO (n.a.), Iran Cultural Heritage, Handcraft and Tourism Organization. Available at: http://www.ichto.ir/

[15] MacDonald, E., Milfont, T., Gavin M. (2015), Thinking Globally But Not Acting Locally?: Expert and Public Perceptions of Environmental Threats and Conservation Actions, in Human Dimensions of Wildlife 20(2): 123-132. https://doi.org/10.1080/ 10871209.2015.963748

[16] Larson, L. R., Stedman, R. C., Cooper C. B., Decker, D. J. (2015), Understanding the multidimensional structure of pro-environmental behavior, in Journal of Environmental Psychology 43: 112-124.

https://doi.org/10.1016/j.jenvp.2015.06.004

[17] Santos, J. R. A. (1999), Cronbach's alpha: A tool for assessing the reliability of scales, in Journal of extension, vol. 37, pp. 1-5.

[18] Spanier, G. B., Thompson, L. (1982), A confirmatory analysis of the dyadic adjustment scale, Journal of Marriage and the Family, pp. 731-738. DOI: $10.2307 / 351593$

[19] Kline, R. B. (2015), Principles and practice of structural equation modeling: Guilford publications.

[20] Schreiber, J. B., Nora, A., Stage, F. K., Barlow, E. A., King, J. (2006), Reporting structural equation modeling and confirmatory factor analysis results: A review, The Journal of educational research, vol. 99, pp. 323-338, 2006. https://doi.org/10.3200/ JOER.99.6.323-338

[21] Hu, L. T., Bentler, P. M. (1999), Cutoff criteria for fit indexes in covariance structure analysis: Conventional criteria versus new alternatives, Structural equation modeling: a multidisciplinary 
journal, vol. 6, pp. 1-55. https://doi.org/10.1080/ 10705519909540118

[22] Marsh, H. W., Hocevar, D. (1985), Application of confirmatory factor analysis to the study of selfconcept: First-and higher order factor models and their invariance across groups, Psychological Bulletin, vol. 97, p. 562, 1985 .
[23] MacCallum, R. (1986), Specification searches in covariance structure modeling, Psychological Bulletin, vol. 100, p. 107.

[24] Proshansky, H. M., Fabian, A. K., Kaminoff, R. (1983), Place-identity: Physical world socialization of the self, Journal of Environmental Psychology, vol. 3, pp. 57-83. DOI: https://doi.org/10.1016/So272-4944 (83)80021-8 